\title{
Digital divide and the role of interactive digital television $^{1}$
}

\author{
Marcio Wohlers, Rodrigo Abdalla F. Sousa, Elia Cia Alves
}

\begin{abstract}
Since its beginning, the interactive Digital Television (iDTV) in Brazil has been anticipated by specialists as a viable and important tool to reduce the digital divide. Nevertheless, few studies have examined to what extent it may be really effective among low-income families so far. This paper analyzes the role of iDTV as an instrument to decrease the digital divide. This assessment was carried out through a survey with a sample of 67 families, selected among a group of 100 families who participated of a pilot experiment, in the city of João Pessoa, located in the Northeastern region of Brazil. The project included four iTVD applications that offered government services and were specially designed, using Ginga middleware, to promote to digital and social inclusion. The survey was composed by a questionnaire containing 102 questions, most of them of closed-ended type. In order to understand iDTV impact in the digital divide decrease, five analytical criteria with respect to user's viewpoint were considered: motivation; correct understanding; friendly use de interfaces; usefulness of the information; and applicability of the knowledge.
\end{abstract}

KeYwords: Digital divide. Interactive Digital Television. Evolution of media. Cognitive analysis.

1 The authors would like to thank World Bank's External Affair Manager, Mr. Sergio Jellinek, and Empresa Brasileira de Comunicação (EBC)'s Superintendent, Mr. André Barbosa, and their respective staff, for financial support and technical assistance for this project, as well as their appreciation of the benefits to be gained from independent research. 


\section{Introduction}

Since its beginning, the interactive Digital Television (iDTV) has been anticipated by specialists as a viable and important tool to reduce the digital divide. Nevertheless, few studies have examined to what extent it may be really effective among low-income families so far. In order to decrease the uncertainties during decision process of policy making it is necessary an accurate evaluation of its expected economic and social effects using both qualitative and quantitative approaches.

Thus, this paper is intended to present an assessment of iDTV as an instrument to decrease the digital divide. The assessment model was applied in a survey with a sample of 67 families, selected among a group of 100 families who participated of a pilot experiment, in the city of João Pessoa, located in the Northeastern region of Brazil. All of them live below the poverty line and have been assisted by a cash transfer program from the Brazilian federal government. The survey was composed by a questionnaire containing 102 questions, most of them of closed-ended type. The project included four iDTV applications that offered government services and were specially designed to promote to digital and social inclusion.

The paper is organized in six sections. Besides this introduction, the second section reviews theoretical concepts of the assessment model. It includes new aspects of the phenomenon of digital divide, which was examined through the perspective of cognitive barriers and learning process. The third section briefly explores the possibilities of TV survival in the Information and Communication Technologies (ICT) world using the approach "life cycle of new media evolution and inter-media struggle for survival in the internet age". The political context that supported the pilot experiment is described in section 4 . Section 5 explains survey's methodology and reveals some of its results. At last, section 6 presents the main findings of this research.

\section{Digital inclusion and learning process}

Aside from the issue of proper infrastructure availability and affordability, digital inclusion is also closely related to the learning process. In a broad sense, if infrastructure is available and affordable, digital inclusion may be achieved by the acquisition of knowledge, which, in turn, modifies one's cognitive perception. This modification may involve language, reasoning, solving of problems, attention or memory. These dimensions are thoroughly altered with the establishment of ICT paradigm.

The competence to participate in communication processes, associated with the new ways of producing, circulating and consuming goods and services in the 
Information Society (IS) ${ }^{1}$, involves the processing, storage and management of huge amounts of data, information and knowledge. The rapid change due to ICT requires very fast learning skills from individuals. Those with greater abilities lead the change of behavior of other people and also the environment's workplace.

The emergence of ICT techno-economic paradigm produced a radical change in technologic and productive fields, as well as in economic development and in social and institutional areas ${ }^{2}$. Some of these changes are still in progress in both developed and developing countries, which include Brazil. However, these modifications manifest in a rather unequal way, according to levels of education, income and culture.

One's competence in ICT involves the development of ability for reflection towards the use of technology and requires a critic view of social and economic changes resulting from the new paradigm. This is similar to the process of reading a book, which demands a minimal cultural level in order to absorb the knowledge registered in the tome. Furthermore, it might be said that IS improvement itself depends on the engagement of the users, meaning, in this case, that they need to become effective participants of this form of social and economic organization. Public and private telecenters, open access to computer labs of public schools and mobile phones with social applications are common ways to promote access to IS and reduce the digital divide ${ }^{3}$.

In the case of digital inclusion, Robin Mansell, a well-known British academic who investigates the development of ICT and its social and economic impacts, suggests that diagnosis and solutions to this problem demand the answeringto the following questions (Mansell, 2000):

1. Which groups are excluded from what?

2. Which are the mechanisms or reasons for this social (digital) exclusion?

3. Once drawn the boundaries between these groups, how narrow or wide are they?

4. Which is the exclusion degree?

\footnotetext{
1 ICT paradigm may also be described under other perspectives: Information Society, when individuals are the direct agents of the new media; Network Society, when new links among human beings and organizations are created; or Knowledge Society, when transmission and assimilation of knowledge are the structural axis of the society.

2 There are already many works on this matter, such as: Freeman and Louçã (2001).

3 For the sake of simplicity and space, this paper will not consider the importance of telecenters or mobile phones. Interested readers may look up in the following works: Maeso y Hilbert (2006) and Kim (2007).
} 
1. Are there many forms of marginalization?

2. Is the exclusion temporary or permanent and what are the chances of overcoming it?

For those countries with high levels of social inequality and few opportunities of inclusion, such as Brazil, these questions are also suitable to direct studies about the correct understanding of the poverty issue. Despite of not being possible to say that poverty, uneven social justice and lack of access to citizenship are the only causes of the digital exclusion, these are major issues that certainly contribute to permanence of digital divide.

One must not forget that the diffusion of a new techno-scientific paradigm (like the ICT paradigm) leads to great changes in the social and economic dimensions of the country, such as: the technologic path, the evolution of job and work structure (both in quantitative and qualitative terms), the modification of the income distribution pattern and also the structure of demand for consumption and production of goods (Perez, 1985).

In order to deepen the concept of digital exclusion, it must be examined in its cognitive dimension. This view complements the above described concept, which highlighted the social and economic aspects of the marginality (exclusion) within the paradigm of the IS. Figure 1, presented by Ávila and Holanda (2006) synthesizes the different types of barriers that cause the digital divide ${ }^{1}$. As portrayed in the figure, the concentric circles represent barriers to digital excluded groups. The arrows of evolution or involution are related to processes of overcoming, or not, these barriers (meaning a virtuous circle or a vicious circle). The central core represents the complete digital inclusion, related to advanced use of ICT and digital content production. Under his perspective, the barriers for digital inclusion were classified in the following levels:

3. Access availability

4. Usability and accessibility

5. Intelligibility

6. Apprehension of contents

7. Creation of contents (complete digital inclusion)

1 For more details, see: Holanda and Dall'Antonia (2006). 
Figure 1. Levels of digital exclusion

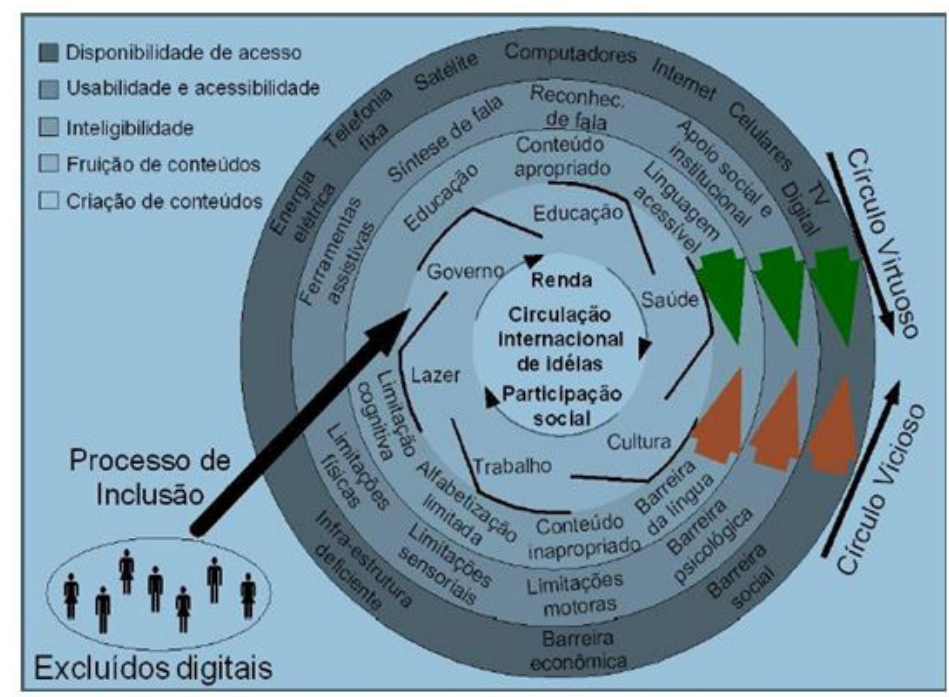

Source: Ávila and Holanda (2006).

Although this figure is mostly self-explanatory, it must be stressed that the three outer concentric circles characterize progressively more intense barriers. On the contrary, the two inner circles refer to content apprehension and content production. For those individuals within the inner circles, digital divide is not applicable anymore.

\section{TV survival in ict world}

The project under evaluation is based on the TV platform. So, it is important to assess the possibility of TV survival in the long run. Many analysts believe that television will soon vanish and will be replaced by new media connected to the internet. However, this prognosis is based on technological determinism and does not include an examination of the competition between the old media (TV) and the new media (internet-based).

Lehman-Wilzig and Cohen-Avigdor (2004) exposed an interesting analysis on the competition between different kinds of media, using an approach similar to the product life cycle. However, the extent and complexity of their model is significantly broader. The analysis focused on the evolution of new media by identifying the competition stage in the industry. The theory was applied to explain the historical development of four major 
kinds of media: newspaper, radio, television and internet. The authors identified six phases of media life cycle, namely:0) birth; 1) market penetration; 2) growth; 3) maturation; 4) defensive resistance; e 5) adaptation, convergence or obsolescence. Figure 2 synthesizes the life cycle of old and new media. Each one of the circles reveals that the respective media has already completed a life cycle.

Figure 2. Life cycle model of new media evolution

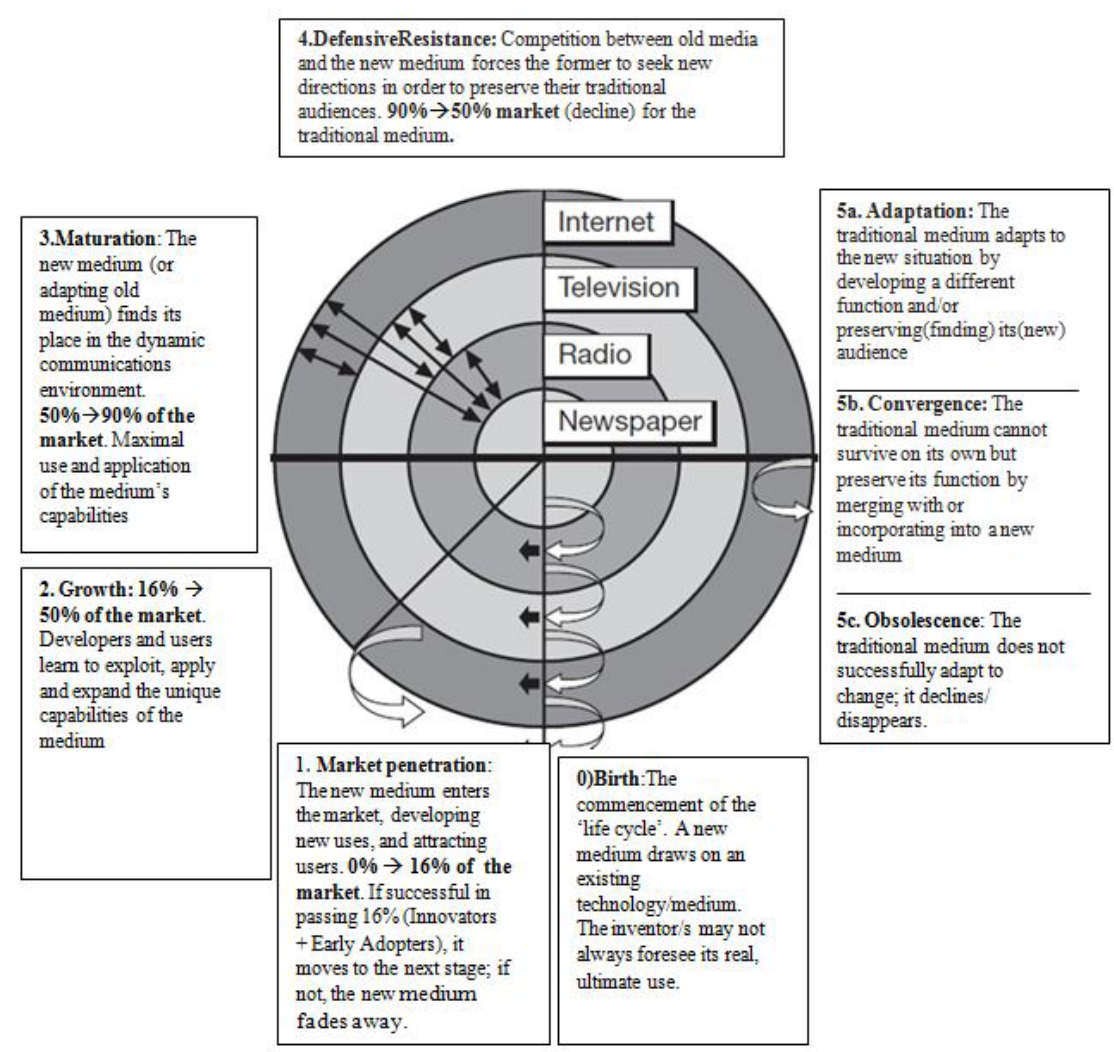

Source: Lehman-Wilzig and Cohen-Avigdor (2004).

Regarding our assessment, the fourth stage illustrates the defensive reaction of the actual TV players. However, in the competitive war between the traditional media of television and the new media transmitted over the internet, it is necessary to differentiate commercial TV from public TV, since their operational models are very different. On the one hand, commercial TV funding is based on the advertising and audience cycle, which 
sells audience in exchange for advertising. On the other hand, public TV budget depends essentially on the government. Despite of this, depending on the governance model implemented, its role may be independent from both private interest and political power.

The new media is taking a lot of audience time and advertisement money from television. Overall spending on advertising in the United States reached a value of US\$ 497.3 billion in 2012. Spending on internet accounted for $18 \%$ of this, while advertisement expenses on TV reached 40\%. Although advertisement spending on TV has grown for many decades, it is now stagnant ${ }^{1}$.In turn, advertising placed in the social networks like Facebook, Twitter and big blogs are still growing. Another difference is that advertisement in the new media has been done in a more subtle way, including interactive advertising and different forms of branding, resulting in a very fluid boundary between content and advertising.

In the United States, it may be verified that TV market is going through adaptation and is converging with internet's technical features. In Brazil, however, it may be seen the beginning of a defensive resistance of actual TV players. About the Latin America context, it is worthy to mention the analysis made by Colombian Jesus Marin-Barbero². He recalls that, until the 1970s (before the emergence of internet), North-American cultural production dominated fiction television programming in Latin American countries. However, from the mid-1970s, soap operas from several countries, in particular Brazil, Mexico and Venezuela, consolidated the modernization and technical capability of their local television networks, initiating exports of these productions. On the one hand, the production of soap operas reflected cultural diversity of Latin American. On the other hand, globalization reduced this affirmative movement of national identity.

\section{Multi-sided platform (MSP)}

In order to a better understanding of the functionality of the iDTV, it is very useful to work with the multi-sided platform approach. A multi-sided platform (MSP), according to the definition of Hagiu \& Wright (2011), represents an organization which allows gains and benefits (values) through direct interaction between the different parts affiliated to the organization. The MSP approach allows the observation and interpretation of the various dimensions of the behavior and the strategies of both groups connected by the platform. Its functionality makes it easier to perform searches, to negotiate prices and

\footnotetext{
1 See Worldwatch Institute. Download in May 29th, 2013 at bit.ly/110dPV1.

2 Jesus Martin-Barbero, a world reputed intellectual, disapproves academic elites that consider the TV as a low quality visual space. His response to this criticism is referenced in Junger Habermas' writings, in particular the concepts of communicative rationality and the public sphere. This paragraph is based on chapter 3 of the book "Los ejercicios del ver - hegemonia visual y ficción televisiva", produced in partnership with German Rey and cited as Martin-Barbero and Rey (2004).
} 
to reduce transaction costs. In general, each part shows a very diverse structure from the other one. Regarding economic transactions, the platform also allows the evaluation of pricing strategies, subsidies and market structures of each part.

It is also worthy to mention that the authors define a "pure"MSP when the parts are affiliated to the platform. However, there is a wide range of definitions between the "pure" MSP and the simple intermediation done by a retailer. The positioning in this range depends on the strategy adopted by the different agents involved.

In general, the terms "platform" or "market" may be used interchangeably, for either two-sided or multi-sided situations. Some examples of markets (platforms) are classic, such as the technology used for debit or credit cards. These platforms connect retailers on one end and consumers on the other. Other examples may be highlighted, such as the telephone networks (platforms), which connect the ones making the calls to the ones receiving. Not only virtual (or digital) platforms may be implemented. A "material" platform is also possible. This case is exemplified by the role of newspapers, which connect the announcers and the buyers. The content exhibition is used to attract readers (one side of the platform).

Anyway, in any two-sided markets, a specific platform allows the contact between providers and users who are interested in making the transactions. Using the same strategy of newspapers, television may also be regarded as a MSP, in which content programming is used to attract spectators and two-sides are connected: product suppliers, who present publicity, on one side; and spectators (consumers), on the other. On the internet, we would have final users, who also buy products and services, and content providers, which are connected to the platform by TCP-IP protocols. On the social networks, such as Facebook, there is a connection between users and software developers and content producers.

These previous examples refer to transactions in the commercial field, aiming to obtain immediate economic results. In the case of iDTV, used in the pilot experiment of Joao Pessoa, the analysis through the "multi-sided platform" approach is not only possible, but extremely useful. It allows, for example, a clear distinction of evolution strategies on both sides. In the case of the low-income families' side, their behavior towards the applications, their usage frequency, their motivation and expectations may be examined. Using this information, the application developers and web designers' side (which also includes universities) are able to define an evolution strategy for applications and products to be made available to the other side. In other words, they may find out more advanced ways for social and digital inclusion.

\section{The political support for the pilot experiment}

The decision to carry out a pilot experiment to assess economic and social effects of iDTV among low-income families was held by Brazilian Communications 
Company (EBC), the Brazilian national public TV broadcaster. EBC is a federal stateowned company, linked to the Communications Secretariat of the Presidency of the Republic.

The project was expected to reveal iDTV potential for digital inclusion, once one of EBC's goals is to encourage and to produce interactive contents aiming at the universalization of electronic services. In particular, it also had the purpose of evidencing economic and social benefits to the people at the bottom of the pyramid. The solution adapted the regular analogical TV, present in 98\% of Brazilian households, to iDTV. This was made possible by installing a low-cost digital-analogical converter, also known as digital set-up box. This device was built using Brazilian technology (Ginga middleware), which made feasible the interaction between people and the channel of e-gov services.

The pilot experiment was located in poor communities in the Northeastern Region of Brazil. According to the table 1, which presents data from 2009, this region exhibits a high percentage of functional illiterate people (30.8\%).

Table 1. Brazil functional illiteracy according to geographic regions, gender and urban or rural areas (15 years old or more) -2009

\begin{tabular}{|c|r|r|r|r|r|}
\hline Regions & \multicolumn{1}{|c|}{ Total } & \multicolumn{1}{c|}{ Male } & \multicolumn{1}{c|}{ Female } & \multicolumn{1}{c|}{ Urban } & \multicolumn{1}{c|}{ Rural } \\
\hline Brazil & 20,3 & 20,9 & 19,8 & 16,7 & 40,7 \\
\hline North & 23,1 & 25,1 & 21,1 & 18,9 & 39,2 \\
\hline Northeast & 30,8 & 33,7 & 28,2 & 24,0 & 50,3 \\
\hline Southeast & 15,2 & 14,5 & 16,0 & 13,8 & 33,6 \\
\hline South & 15,5 & 14,9 & 16,1 & 13,5 & 25,8 \\
\hline Center-west & 18,5 & 19,0 & 17,9 & 16,3 & 34,2 \\
\hline
\end{tabular}

Source: IBGE (2010)

The pilot experiment did not count on any public funds to be implemented. It was made possible by an integrated network of researchers and companies, which was settled to execute the project. On the technical side, an iDTV broadcast network was deployed to cover three slums in the city of João Pessoa, the capital of Paraiba State. It was designed to reach people extremely deprived of income, access to school and culture. 


\section{Field survey and its results ${ }^{1}$}

\section{PILOT EXPERIMENT'S STRUCTURE}

The MSP approach may accurately characterize the pilot experiment. iDTV platform allows the interaction between low-income families, on one side, to policy makers, on the other. The supported families receive information and knowledge, by the use of the broadcast infrastructure, digital converters and content application to promote digital inclusion. Because the platform has a number of integrated modules, it is very complex and includes many players. There are, at least, three different kinds of institutions involved, namely: A) universities and research centers, that supported the broadening of knowledge in technologic fields, as well as in social and cultural areas; B) public sector, encompassing organizations that either define and apply public policies or support and foster the functioning of the system; C) private and public companies, which the developed technology and offer new products to the market. In the case of the project, the list of the organizations involved (although risking the omission of some of them) include, respectively:a) Lavid (digital video lab) and Pontifícia Universidade Católica do Rio de Janeiro (PUC-RJ), which form a network of researchers since 1995 and have, among other innovations, developed Ginga middleware; b) EBC, Ministry of Communications (Minicom) and National Bank for Economic Development (BNDES) - the latter created in 1997 the program ProTVD (a supporting program for the implementation of the Brazilian iDTV) ; and c) TOTVS, D-Link and other manufacturers of set-up boxes, as well as its parts, components and embedded software.

The project was implemented by a service provider (EBC), which broadcasted a unidirectional digital carrier to a certain area that covered the participant families of the pilot experiment in the slums of Joao Pessoa. The iDTV service provider can offer interactive applications from different natures, including government and commercial ones. There are two possible ways to implement interactive applications, namely local or full interactivity. Local interactive applications offer only the content stored in the digital converter (but it is possible that it be regularly updated), while full interactive applications also perform remote transactions. For the latter kind, it is necessary to implement a return (or reverse) channel, which is employed to transmit information back to the service provider. The interactivity used in the pilot experiment was an intermediary level between the two previously mentioned. There was effectively a return channel implemented, using mobile $3 \mathrm{G}$ technology, but it was employed only to measure how frequent the application utilization was².

\footnotetext{
1 The authors would like to thank to the project managers of the pilot experiment for disclosing the surveyed data for this paper. The final report is expected to be released during May, 2013.

2 For more details, see: Esther, Osorio, Antonini and Pataca (2009).
} 
The pilot experiment had the following assumptions:

- Permanence of free-to-air TV: Because of fragmentation of means of communication and arrival of new media, TV lost its centrality. Nevertheless, it has established itself as popular medium, mainly among functional illiterate people.

- The use of colors, icons, characters and videos: They are very important to differentiate functions and guide through the services on iDTV. As a matter of fact, colors, icons and characters make communication easier and they are commonly used for orientation in places with circulation of masses (subway, streets, malls, airports, etc). In the figure 3, there are depicted an image from TV screen and a picture of the remote control used in the project.

- Knowledge diffusion about iDTV: From a sociologic viewpoint, the "favelas"(slums) present a fast circulation way for basic information about consumption habits and experience reports, favoring the knowledge diffusion about iDTV operation.

Figure 3. Images from TV screen and remote control used in the project
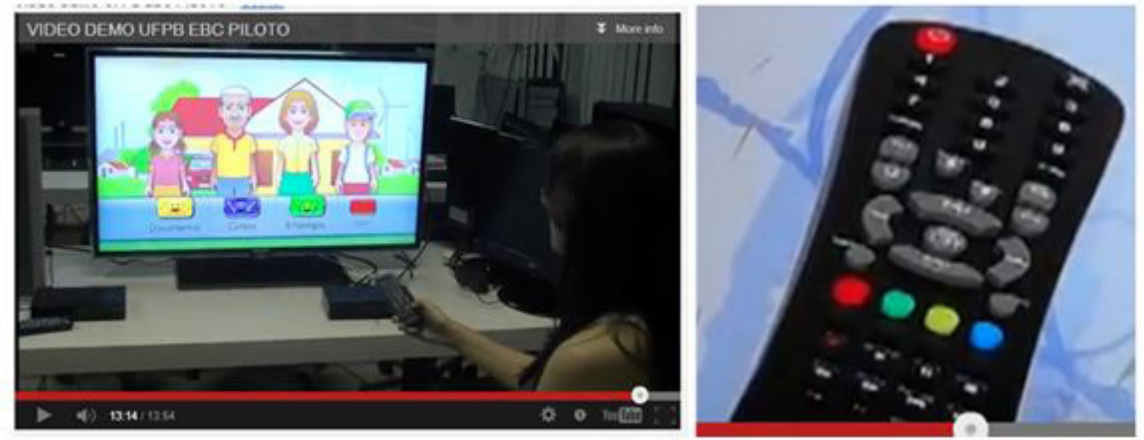

\section{SAMPLE SELECTION}

Some criteria defined the participants in the pilot experiment. The location of the project was defined to be in one of the States with lowest GDP per capita. The participants of the pilot experiment should be in absolute poverty. Moreover, the sample size and selection was conditioned to technical viability of the project.

Thus, the chosen location was the State of Paraiba, located in the Northeastern Region of Brazil, which was at 24thrankin the list by Gross Domestic Product (GDP) per 
capita among the 27 Federal States'. To comply with the absolute poverty criterion, a group of families registered in the federal cash transfer program , called "BolsaFamilia", which covers around 11 million families, was selected. The sample size (100 families) was determined by the number of set-top boxes that were granted to the pilot experiment. The decision to implement the project in urban area had two reasons. First, it is technically easier to implement a network in denser zones, such as urban areas. Secondly, from a sociological perspective, urban poverty is a phenomenon more complex than the rural poverty.

\section{E-GOV. SERVICES AVAILABLE IN THE PILOT EXPERIMENT}

Four electronic government (e-gov) applications were available in the iDTV service channel:

- Social benefits: information about benefits and obligations related to "BolsaFamilia" - blue button;

- Employment and courses: information about personal documents, qualification programs, and available jobs - yellow button. While information about personal documents was essentially static, information about courses and jobs was regularly updated. The update process is initiated by the City Hall staff, which already collects data on courses and jobs available in the city. The list is handed over (off-line) to the service provider, which broadcasts the new content to the interactive applications stored in the digital converters. When users perceive an opportunity for course or job, they should appear in person to the City Hall or to the training facility.

- Health: information about health care and common diseases, as well as directions to the nearest drugstore offering subsidized medicines - green button;

- Financial education: a short course on financial education prepared by a stateowned bank- red button.

All applications had explanatory videos, exploring the use of colors, icons and characters, in order to facilitate the correct understanding of the information by the users.

\section{MAIN RESULTS}

The results were measured by descriptive statistics and were organized accordingly to the following criteria: 1) Motivation, 2) Correct understanding; 3) Friendly use of interfaces; 4) Usefulness of the information and 5) Applicability of knowledge.

\footnotetext{
1 The absolute variation of GDP per capita among the last four States in the ranking is very small.
} 
1) Motivation: it was analyzed by users' attitude towards the offerings of iDTV. About 20\% of the users did not use any application. In most cases, it was due to technical problems (lack of signal), but there were also some cases of users that did not have any interest on the applications or were afraid of dealing with the equipment. Graphic 1 shows that the distribution for the variable of "number of applications used" is quite uniform: 15\% of the respondents declared that had used only one application; about $20 \%$ had utilized two applications; $25 \%$, three applications; and 19\% had experimented all of them. This variable indicates that, in general, people have had a positive attitude towards the applications. Some interviewees complained about the repetitive programming. Considering that almost $65 \%$ of the respondents have used more than one application, it may indicate that, if there had been a greater supply, it would have been probably consumed too.

\section{Graphic 1. Number of applications used}

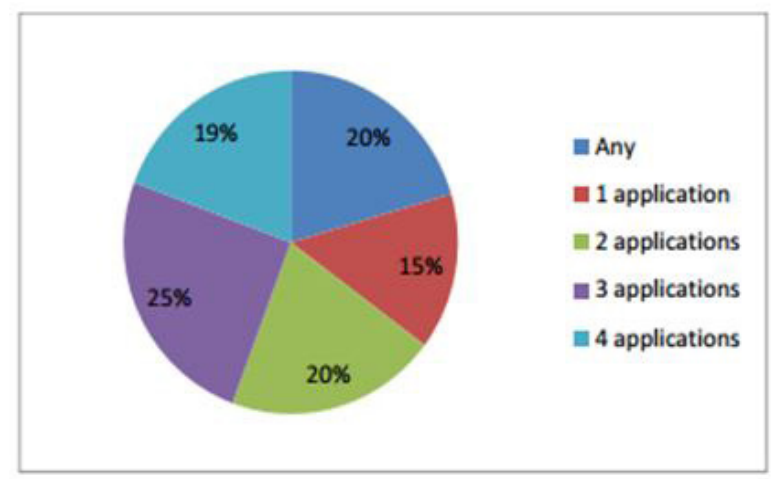

Among all the applications, "Social Benefits" and "Employment and courses" were the most used ones, as depicted in graphic 2. "Social benefits" was the first one. Positive behaviors can validate the great use of the application. For instance, some users reported that, after checking their own situation in the social programs, they invited friends, relatives and neighbors to use the application and also check their status. This is a very important result, because it demonstrates that users have become so motivated by the application that they have shared the new obtained information within their social networks. 
Graphic 2. Use of applications

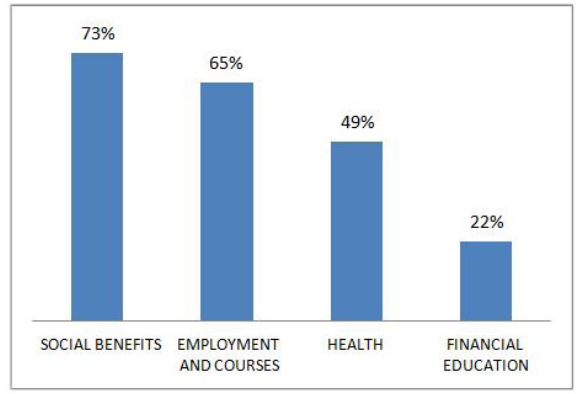

2) Correct understanding: this variable was evaluated purely in a qualitative manner. Correct understanding was vital to the pilot experiment, since it was one of its key premises (assumption II). The use of colors to differentiate between the four applications worked fine. Besides that, the utilization of icons and characters was fundamental for the illiterates. Some respondents have declared that explanatory videos showing how to interact with the applications were essential to their comprehension, since they have understood what needed to be done without any help from another person. The "Financial education's application, which did not offer any verbal explanation, was the least used and considered the most difficult to deal with among them all. All in all, it was verified that the applications with interactive stories had better results, because they used digital formats to offer participatory, immersive and engaging experiences. For example, some interviewees have reported that they decided to see a doctor, schedule a check-up exam or follow up with their children's vaccines, after interacting with the "Health" application.

3) Friendly use of interfaces: this variable captured users' attitude towards the ease of use of the applications. It also indicates a tendency of users to actively interact with the applications. The variable was assessed by values attributed by users. Based on their opinion, table 2 reveals which applications users found easier to use and which ones they found more difficult. Any application that acquired an "easy" value above $50 \%$ is considered satisfactory.

Table 2. Application's facility grade

\begin{tabular}{l|rr}
\hline Application & Easy & Difficult \\
\hline Social benefits & $66 \%$ & $44 \%$ \\
Employment and courses & $81 \%$ & $19 \%$ \\
Health & $79 \%$ & $21 \%$ \\
Financial education & $53 \%$ & $47 \%$ \\
\hline
\end{tabular}


As observed in table 2, the easiest application was the "Employment and courses", followed by the "Health" one. The hardest ones were the "Social benefits" and the "Financial education's applications. These results confirm that the best applications to interact with were the ones that reinforced the use of colors and icons. Characters also played an important role, since they presented ordinary problems, with which the audience has identified itself. In any case, results from the application "Employment and courses" are considered a positive result for the pilot experiment, since achievement of a formal job position is a major opportunity for life improvement of those families.

4) Usefulness of the information: this variable measures the quality and the originality of information. The survey also collected suggestions for application improvements. The application "Employment and courses" had the best scores on this variable. All respondents that were looking for a job declared that it was very useful. Among those who were looking for courses, 89\% declared that it was useful or very useful. Regarding the information on how to get personal documents, it was useful or very useful, according to $83 \%$ of the interviewees. Despite of the positive feedback, many users suggested improvements, such as to exhibit more detailed information and to promote more frequent updates. As exposed in graphic 3, information about health issues were considered useful or very useful by $82 \%$ of the respondents. Interviewees also suggested a list of other diseases that they would like to receive more information about. The "Social Benefits" application stayed at the third place. However, it was very important for many respondents that had complications to access its benefits."Financial education" application ended at the last position, mainly because its interface was quite unfriendly for illiterate users (it did not use audio or video, only written text). Consequently, many users were not able to understand its content, resulting in difficulties to find it useful.

\section{Graphic 3. Usefulness of the information}

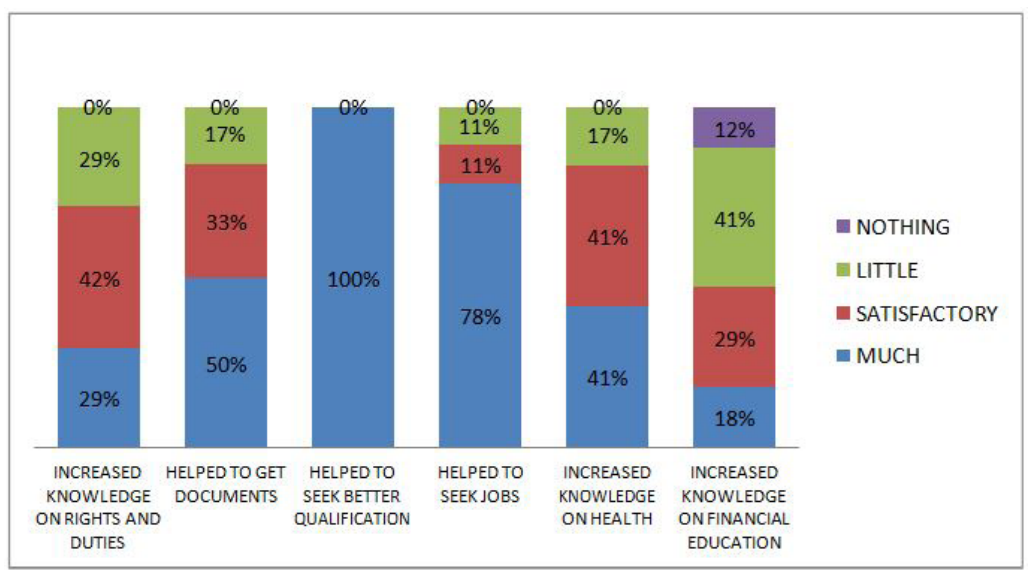


5) Applicability of knowledge: this variable attempted to measure if users have effectively absorbed the information and applied in their day-to-day life. Graphic 4 illustrates that almost two-thirds of interviewees declared that they have perceived economic benefits. In particular, 2\% of respondents affirmed that they have increased household income, by getting a job. Once users realize how much time and money has been saved in transaction costs to obtain information, they value higher the offered services through iDTV.

\section{Graphic 4. Applicability of knowledge}

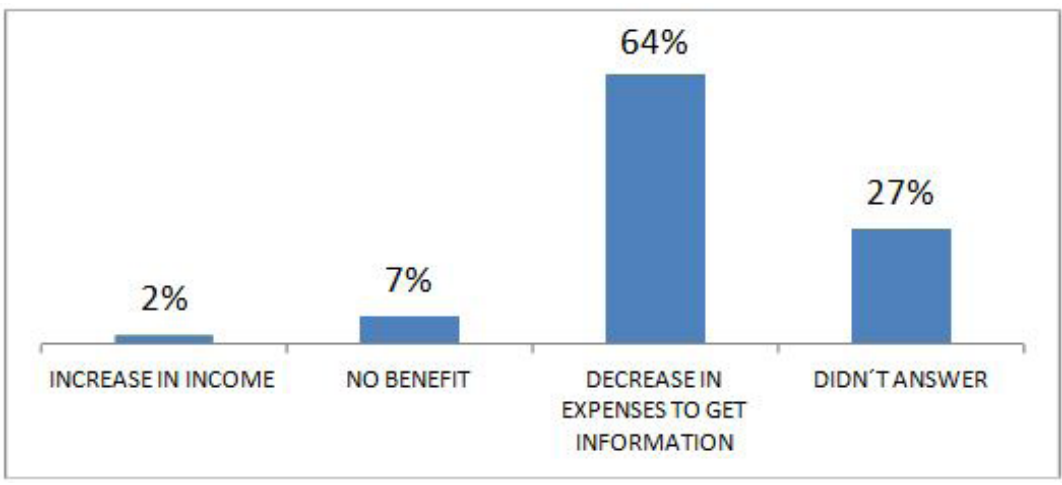

Therefore, even considering only a small sample, it was possible to find positive results regarding the use of iDTV as an instrument for social and digital inclusion.

\section{Concluding remarks}

The survey presented in this paper assessed the first pilot experiment in Brazil on the feasibility of iDTVin order to reduce the digital divide. Other alternatives of public policies with the same goal are also in progress, such as implementation of public and private telecenters or public access to the computer labs of public schools. Some telecenters are also part of pilot experiments where human-computer interface is designed to be quite friendly to different needs of the poorest families. In such cases, the deployment of infrastructure (both hardware and software) is relatively expensive.

The great advantage of iDTV platform is that TV sets are present in $98 \%$ of Brazilian households and low-income families are very familiar with their operation and functionalities. In other words, electronic services will be more convenient to users, as they will not need to leave their homes to access these facilities in telecenters or public schools anymore, but simply use the features of well-known terrestrial TV, equipped with a specific 
set-up box. The use of the remote control (an elementary keyboard) and the interaction with the TV screen (similar of the computer) represents a first step (unconscious) of the computer use by a low income person. Insofar with use of the iDTV during a long period will be easier for him to assimilate the apparatus runs as a computer.

The survey examined five aspects of social and digital inclusion. Two of them had very important results: the usefulness of the information and the applicability of the knowledge. For instance, in the case of the application "qualification and jobs", 89\% of interviewees declared it was very useful to find the best courses and $100 \%$ considered it useful for looking for jobs. With respect to the applicability of the knowledge, 64\% of respondents reported that the knowledge provided by iDTV applications resulted in cost reduction for information search.

Above mentioned data allow to conclude that iDTV was responsible for a significant increase in digital and social inclusion. The research also examined the cognitive dimension of digital divide, composed by psychological, intelligibility and usability barriers. In this respect, it was observed that iDTV and its applications may be employed to minimize these barriers, especially when they explore the combination of video and text, using an interactive and friendly interface (use of color, icons and characters).

From a technological perspective, the Brazilian Ginga middleware, which has been locally developed, has adequately worked and no problem was reported during the pilot experiment. However, Ginga is still an evolving technology. Therefore, the demonstration of its feasibility aids to expand public and private funding, needed to support further research and development required to improve its performance. It is worthy to note that there is already a network of Latin American researchers in place, who has been periodically promoting seminars to discuss Ginga's technical evolution, interactive applications of terrestrial digital TV, among other issues.

The main findings of this research allow us to anticipate that iDTV has a very large potential for digital inclusion and technological development, by two reasons. First, iDTV technology may facilitate the development of a large number of applications, exploring network externalities supported by the Brazilian digital public broadcasting TV. Secondly, many factors affect the economic impacts of the applications. For example, the higher the originality of the information, the greater will be the impact. Similarly, the lower the access to information by target groups, the greater will be the impact

Digital inclusion of low-income families in ICT world, which revolutionized consumption habits and production forms, is one of the greatest challenges for the Brazilian society and all Latin American community. iDTV, as well as public and private telecenters and mobile phone with social applications, may contribute for reducing the digital divide. Nevertheless, connections between virtual and real worlds cannot be established by an occasional and fortuitous way, subordinated to market forces that provoke other kinds of unfairness. Public policies to digital inclusion should perform an essential role in promoting citizenship, social justice and community integration. 


\section{References}

Ávila, I. and Holanda, G (2006) Inclusão Digital no Brasil. In Átila de Souto, Juliano Dall'Antonia and Giovanni Holanda (Eds.) As cidades digitais no mapa do Brasil - Uma rota para a inclusão social. Ministério das Comunicações. Brasilia.

Esther, M., Osorio, A., Antonini J. e Pataca, D. (2009). Análise do potencial de TV interativa no Brasil, in Cadernos CPqD Tecnologia, julho/dezembro, v. 5, n. 2, 65-81.

Freeman, C. and Louçã, F. (2001). From the Industrial Revolutions to the Information Revolution. Oxford University Press, Oxford.

Hagiu, A. and Wright, J. (2011) Multi-Sided Platforms. Working Paper, Harvard Business School.

Holanda, G. and Dall'Antonia, J. (2006) An Approach for e-inclusion: Bringing illiterates and disabled people into play, in Jounal of Technology and Management, v. 1, n. 3.

IBGE (2010). Síntese de indicadores sociais: uma análise das condições de vida. Coleção Estudos e Pesquisas n. 27. IBGE.

Jonathan, F. and Lessiter, J. (2003) Using Attitude Based Segmentation to Better Understand Viewers' Usability Issues with Digital and Interactive TV, in Working Paper i2 media research limited, Department of Psychology, Goldsmiths College, University of London New Cross. Available at: https://www.brighton.ac.uk/cem/courses/postgraduate/pgpit/ euroitv/euroitv03/Papers/Paper3.pdf . Download in: 28/04/2013.

Kim, M. (2007) Pro Poor Mobile Capabilities: Service Offering in Latin America and the Caribbean, in Mobile Opportunities: Back Ground Papers, IDRC-DIRSI.

Maeso, 0. y Hilbert, M. (2006) Centros de acceso público a las tecnologías de información y comunicación en América Latina: características y desafíos. CEPAL, IDRC y @ LIS.

Mansell, R. and Steinmueller, W. S. (2000). Mobilizing the information society-Strategies for growth and opportunity, Oxford University Press, New York.

Martin-Barbero, J. y Germán, R. (1999). Los ejercicios Del ver-Hegemonia audiovisual y ficción televisiva. Editorial Gedisa, Barcelona.

Perez, C. (1985). Microelectronics, Long Waves and World Structural Change: New Perspectives for Developing Countries. in World Development, v. 13, n. 3, 441-463.

Sam Lehman-Wilzig and Nava Cohen-Avigdor (2004). The natural life cycle of new media evolution: Inter-media struggle for survival in the internet age, in New Media Society, 6, 707. Available at: http://nms.sagepub.com/cgi/content/abstract/6/6/707, download in $28 / 04 / 2013$. 